The University of Maine

DigitalCommons@UMaine

$1-1-1899$

\title{
The Effect of Magnetization upon the Elasticity of Rods
}

J. S. Stevens

H. G. Dorsey

Follow this and additional works at: https://digitalcommons.library.umaine.edu/phy_facpub

Part of the Physics Commons

This Article is brought to you for free and open access by DigitalCommons@UMaine. It has been accepted for inclusion in Physics and Astronomy Faculty Scholarship by an authorized administrator of

DigitalCommons@UMaine. For more information, please contact um.library.technical.services@maine.edu. 


\section{THE EFFECT OF MAGNETIZATION UPON THE ELASTICITY OF RODS.}

By J. S. Stevens and H. G. Dorsey.

IN the Physical Review, Vol. II., No. 4 and Vol. III., No. 6, is 1 described a series of important experiments which show the relation between temperature and elasticity in a wire. In one of the papers the statement was made that the results seem to indicate that the magnetizing effect of the current through the wire increases the modulus of elasticity. The increase in temperature in the wire was produced by sending a current directly through it, and also by sending a current through the helix which surrounded it. The author stated that " the magnetization produced by the first method had no appreciable effect on the result, and that if there is any difference in the effects produced upon the elasticity of a wire by magnetizing it, that difference is too small to be detected with any certainty by this experiment."

This paper contains the results of some experiments whose object was to test the effect of magnetization upon the modulus of elasticity by the application of interference methods of measurement.

The accompanying figure will make clear the method of operation. A series of carefully prepared rods ${ }^{1}$ whose dimensions are given below, were in turn supported in the ordinary manner for determining the elastic modulus at points $3.2 \mathrm{~cm}$. from their ends on adjustable knife-edges. In the center of the rod suspended from a hook was the load causing the deflection, and on the upper surface one of the mirrors of an interferometer. Surrounding the rod was first an air space, then a chamber for the passage of a stream of water, and on the outside two series of coils having a resistance of

1 The same rods were used by Mr. C. P. Weston in his experiment described in the Physical Review for May, I899. 
54.4 ohms each. When the rod was bent by the deflecting weight the interference fringes were found in the usual manner. A sodium lamp was used as the source of light radiations. It is obvious that any change in the modulus of elasticity due to magnetizing the bar would produce a corresponding motion in the fringes seen in the mirror.

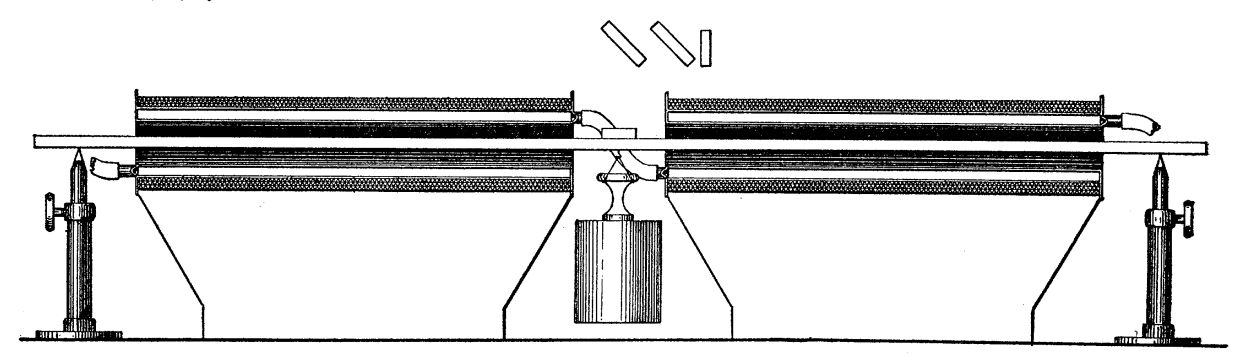

Fig. 1 .

The great source of error to be guarded against in this work was the effect on the modulus due to heat. That this was eliminated will, we think, appear from the following considerations :

(a) A stream of water was caused to run through the chamber between the coils and the rod while the observations were made.

(b) The motion of the fringes appeared to be instantaneous when the current was turned on. When the circuit was kept closed for some time a creeping motion of the fringes (probably due to temperature changes) was observed.

(c) A copper bar of the same dimensions as those previously used was substituted, and no such instantaneous motion of the fringes was observed.

(d) The fringes came back to their initial position immediately when the current was turned off, when the steel rod was used.

(e) A thermometer reading by estimation to hundredths of a degree showed no appreciable change of temperature in the air surrounding the rod while the displacement of the fringes was being measured.

Among the difficulties encountered were :

(a) The arrangement of the mirrors so as to get good fringes. The conditions for producing interference were extremely unfavorable as the adjustment of the mirror on the bar had to be made en- 
tirely by hand. It was supported on wax of such a consistency that it could be easily moved, but when once adjusted it kept its place. The difficulty here referred to, however, was one which needed only practice and patience to overcome, and whenever the observations were recorded the fringes were sufficiently distinct.

(b) Although the apparatus was mounted in a basement laboratory, on a stone slab supported by a brick foundation which did not come in contact with the floor or any other part of the building, a clock striking four stories above it caused a rhythmical motion of the fringes. It may be judged from this illustration that the work had to be done at such times as we could find the building free from ordinary disturbances.

(c) Another difficulty was encountered at first arising from the use of homogeneous light, and the consequent similarity of the fringes. With the mirror adjustments used here it would have been next to impossible to have obtained the colored fringes, which may readily be identified; but it was soon found that the displacements were never of an order of magnitude greater than one wave-length, and therefore the necessity of identification was avoided.

The following data were employed :

$\begin{array}{lc}\text { Length of rods, } & 66.3 \mathrm{~cm} . \\ \text { Distance between knife-edges, } & 60.0 \text { “" } \\ \text { Breadth of rods, } & \text { I.0 “ } \\ \text { Thickness of rods, } & 0.54 \text { “" } \\ \text { Length of magnetizing helix, } & 53.0 \text { “ } \\ \text { Number of layers of wire, } & 9.6 \\ \text { Number of turns of wire, } & 7026 . \\ \text { Minimum current used, } & 0.12 \text { amp. } \\ \text { Maximum current used, } & 0.82 \text { “ } \\ \text { Number of turns per cm., } & \text { I } 32 .\end{array}$

In the tables which follow are shown the current, the magnetizing force, the intensity of magnetization and the accompanying displacement of the fringes. In every case the direction of displacement indicated an upward movement of the mirror, and hence an increase in the modulus of electricity. 
TABLE I.

STEEL BAR. LOAD IK.

\begin{tabular}{c|c|c|c}
\hline Current in amperes. & Magnetizing force. & Intensity. & $\begin{array}{c}\text { Displacement in } \\
\text { wave-lengths. }\end{array}$ \\
\hline 0.46 & 77.5 & A nearly uniform & 0.06 \\
0.54 & 89.6 & intensity & 0.15 \\
0.57 & 93.8 & of about 700. & 0.20 \\
0.60 & 99.6 & & 0.25 \\
0.64 & 106.2 & & 0.38 \\
0.66 & 108.7 & & 0.45 \\
0.68 & 112.9 & & 0.50 \\
0.71 & 117.9 & & 0.50 \\
0.75 & 124.5 & & 0.63 \\
\hline
\end{tabular}

TABLE II.

STEEL BAR. LOAD $1 / 2 \mathrm{~K}$.

\begin{tabular}{c|c|c|c}
\hline Current in amperes. & Magnetizing force. & Intensity. & $\begin{array}{c}\text { Displacement in } \\
\text { wave-lengths. }\end{array}$ \\
\hline 0.44 & 73.0 & $\begin{array}{c}\text { A nearly uniform } \\
\text { intensity }\end{array}$ & 0.06 \\
0.45 & 74.6 & 0.06 \\
0.46 & 77.5 & of about 700. & 0.06 \\
0.62 & 102.9 & & 0.13 \\
0.64 & 106.2 & & 0.19 \\
0.65 & 107.9 & & 0.25 \\
0.66 & 109.6 & & 0.25 \\
0.68 & 112.9 & & 0.31 \\
0.71 & 117.9 & & 0.50 \\
0.75 & 124.5 & & 0.50 \\
\hline
\end{tabular}

TABle III.

WROUGHT IRON BAR. LOAD I K.

\begin{tabular}{c|c|c|c}
\hline Current in amperes. & Magnetizing force. & Intensity. & $\begin{array}{c}\text { Displacement in } \\
\text { wave-lengths. }\end{array}$ \\
\hline 0.12 & 19.9 & 389.7 & 0.08 \\
0.15 & 24.9 & 516.5 & 0.22 \\
0.27 & 44.9 & 735.2 & 0.28 \\
0.33 & 54.1 & 838.2 & 0.35 \\
0.38 & 61.3 & $\ldots \ldots \ldots$ & 0.38 \\
0.54 & 89.7 & $\ldots \ldots$. & 0.48 \\
\hline
\end{tabular}


TABLE IV.

WROUGHT IRON BAR. LOAD $1 / 2 \mathrm{~K}$.

\begin{tabular}{c|c|c|c}
\hline Current in amperes. & Magnetizing force. & Intensity. & $\begin{array}{c}\text { Displacement in } \\
\text { wave-lengths. }\end{array}$ \\
\cline { 1 - 2 } 0.16 & 26.6 & 615.1 & 0.20 \\
0.33 & 54.8 & 730.0 & 0.50 \\
0.43 & 71.6 & 838.2 & 0.63 \\
0.60 & 99.6 & 868.8 & 0.75 \\
0.76 & 125.9 & 1075.0 & 0.88 \\
\hline
\end{tabular}

Discussion of Results.

The difficulties encountered in making these observations, and the fact that it was necessary to make them quite rapidly conspired to render the results recorded in the last columns of the tables rather unreliable as quantitative measurements. So far as practicable, however, they represent the mean of several observations taken by each of us. If they were plotted either with the magnetizing force or the intensity of magnetization they would not yield a straight line or any other regular curve. In every case, however, an increase of current was accompanied by an increased displacement. In the case of the steel bar it was necessary to keep the current within a limited range, and as shown in the tables the intensity remained nearly constant. With the wrought iron we were able to use a greater range of current and secured a greater deviation in the displacement column.

The following may be set down as the results of the experiment:

(a) The modulus of elasticity of wrought iron and steel increases with magnetization.

(b) In the case of steel little difference was observed for loads of $\mathbf{I}$ $\mathrm{K}$ and $1 / 2 \mathrm{~K}$. In the case of wrought iron the smaller load gave the greater displacement when equal magnetizing forces were used.

Physical Laboratory, University of Maine. 